\title{
FIXED POINT THEOREMS FOR SET-VALUED MAPPINGS AND VARIATIONAL PRINCIPLES IN UNIFORM SPACES WITH $w$-DISTANCES
}

\author{
RAÚL FIERRO \\ Instituto de Matemáticas, Pontificia Universidad Católica de Valparaíso \\ E-mail: raul.fierro@pucv.cl \\ Instituto de Matemáticas, Universidad de Valparaíso \\ E-mail: raul.fierro@uv.cl
}

\begin{abstract}
By making use of $w$-distances, for set-valued mappings defined on uniform spaces, we generalize some classical results in the existing literature of nonlinear analysis, such as, Bishop-Phelps and Caristi's fixed point theorems, Ekeland's $\epsilon$-variational principle and the nonconvex minimization theorem according to Takahashi. Our version of Caristi's fixed point theorem is used to prove existence of fixed points on uniform spaces for some contractions such as weak, Chatterjea and Kannan contractions defined by means of $w$-distances. The results introduced in this paper generalize others existing in the literature of nonlinear analysis.

Key Words and Phrases: Caristi's theorem, fixed point, uniform spaces, variational principle, $w$-distance.
\end{abstract}

2010 Mathematics Subject Classification: 47H10, 58E30, 54E15, 06A06.

Acknowledgment. This work was partially supported by Chilean Council for Scientific and Technological Research, under grant FONDECYT 1120879.

\section{REFERENCES}

[1] I. Altun, M. Imdad, Some fixed point theorems on ordered uniform spaces, Filomat, 23(2009), no. $3,15-22$.

[2] V. Berinde, Approximating fixed point of weak contractions using the Picard iteration, Nonlinear Anal. Forum, 9(2004), no. 1, 43-53.

[3] E. Bishop, R.R. Phelps, The support functionals of a convex set, Proceedings of Symposia in Pure Mathematics VII, Convexity, American Math. Soc., 7(1963), 27-36.

[4] N. Bourbaki, Elements of Mathematics, General Topology. Part 2, Hermann, Paris, 1966.

[5] A. Brøndsted, On a lemma of Bishop and Phelps, Pacific J. Math., 55(1990), no. 2, 335-341.

[6] J. Caristi, Fixed point theorem for mappings satisfying inwardness conditions, Trans. Amer. Math. Soc., 215(1976), 241-251.

[7] S.K. Chatterjea, Fixed-point theorems, C.R. Acad. Bulgare Sci., 25(1972), 727-730.

[8] W.S. Du, On Latif's fixed point theorems, Taiwanese J. Math., 15(2011), no. 4, 1477-1485.

[9] I. Ekeland, On the variational principle, J. Math. Anal. Appl., 47(1974), no. 3, 324-353.

[10] I. Ekeland, Nonconvex minimization problems, Bull. Amer. Math. Soc., 1(1979), no. 3, 443-474.

[11] A.H. Hamel, Phelp's lemma, Daneš drop theorem and Ekeland's principle in locally convex spaces, Proc. of the Amer. Math. Soc., 131(2003), no. 10, 3025-3038. 
[12] A.H. Hamel, Equivalents to Ekeland's variational principle in uniform spaces, Nonlinear Anal., 62(2005), no. 5, 913-924.

[13] S. Iemoto, W. Takahashi, H. Yingtaweesittikul, Nonlinear operators, fixed point and completeness in metric spaces, Fixed Point Theory and its Applications (Eds. L.J. Lin, A. Petrusel, H.K. Xu), Yokohama Publishers, Yokohama, 2010, 93-101.

[14] O. Kada, T. Suzuki, W. Takahashi, Nonconvex minimization and fixed point theorems in complete metric spaces, Math. Japonica, 44(1996), no. 2, 381-391.

[15] R. Kannan, Some results on fixed points-II, Fundamenta Math., 76(1969), no. 4, 405-408.

[16] A. Latif, Multivalued generalizations of the Kannan fixed point theorem, Filomat, 26(2012), no. 5, 929-933.

[17] A. Latif, W.A. Albar, Fixed point results for multivalued maps, Intern. J. Contemporary Math. Sci., 2(2007), no. 23, 1129-1136.

[18] Z. Liu, Y. Lu, S.M. Kank, Fixed point theorems for multi-valued contractions with w-distance, Applied Math. Comput., 224(2013), 535-552.

[19] N. Mizoguchi, A generalization of Brøndsted' results and its applications, Proc. Amer. Math. Soc., 108(1990), no. 3, 707-714.

[20] N. Shioji, T. Suzuki, W. Takahashi, Contractive mappings, Kannan mappings and metric completeness, Proc. Amer. Math. Soc., 126(1998), no. 10, 3117-3124.

[21] T. Suzuki, Several fixed point theorems in complete metric spaces, Yokohama Math. J., 44(1997), no. 1, 61-72.

[22] T. Suzuki, Generalized distance and existence theorems in complete metric spaces, J. Math. Anal. Appl., 253(2001), no. 2, 440-458.

[23] T. Suzuki, W. Takahashi, Fixed point theorems and characterizations of metric completeness, Topol. Meth. Nonlinear Anal., 8(1996), no. 2, 371-382.

[24] W. Takahashi, Existence theorems generalizing fixed point theorems for multivalued mappings, Fixed Point Theory and Applications (M.A. Théra and J.B. Baillon-eds.), Pitman Research Notes in Mathematics Series, Vol. 252, Longman Sci. Tech., Harlow, 1991, 397-406.

[25] W. Takahashi, N.C. Wong, J.C. Yao, Fixed point theorems for general contractive mappings with $w$-distances in metric spaces, J. Nonlinear Convex Anal., 14(2013), no. 3, 637-648.

[26] J.D. Weston, A characterization of metric completeness, Proc. Amer. Math. Soc., 64(1977), no. $1,275-278$.

Received: May 14, 2015; Accepted: February 20, 2016. 